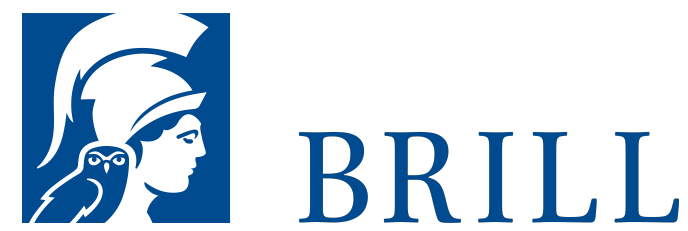

\title{
Geist, Bedeutung, Natur
}

Eine Kritik naturalistischer Theorien begrifflichen Gehaltes

Author: Wolf-Jürgen Cramm

Lassen sich Geist und Bedeutung "naturalisieren"? Damit ist genauer die Frage gemeint, ob sich einerseits Gedanken, Überzeugungen oder Gründe, die wir haben, zu denen wir gelangen oder aus denen wir folgern oder handeln können, andererseits die Bedeutung sprachlicher Ausdrücke, mit denen wir uns -- auch über Geistiges -- verständigen, als etwas begreifen lassen, was irgendwie in Begriffen eines bloßen Geschehens erklärbar ist oder mit etwas bloß Geschehendem identisch ist. In diesem Buch wird dafür argumentiert, dass die Antwort auf diese Frage negativ ausfällt. Dabei geht es nicht allein um eine Detailkritik unterschiedlicher naturalistischer Ansätze oder Theorien. Die Probleme sind, wie deutlich werden soll, von grundsätzlicher Art: Die kausale, funktionale oder physische Begrifflichkeit, in der wissenschaftliche Theorien oder auch alltagsweltliches Sprechen über Natürliches ihre Gegenstände klassifizieren und individuieren, ist nämlich unvereinbar mit der Einstellung, in der wir geistige Einstellungen (oder Handlungen) zuschreiben oder bekunden bzw. Aussagen über die Bedeutung sprachlicher Ausdrücke machen. Für solche Redeweisen ist eine soziale Praxis der Zuschreibung und Übernahme von Verantwortung sinnkonstitutiv, die sich ihrerseits nicht als ein vorfindliches Geschehen verstehen lässt.

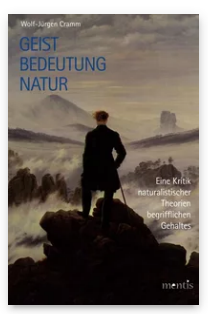

Pages: 391

Seiten

Language:

German

Subjects:

General,

Philosophy

Publisher: Brill | mentis

E-Book (PDF)

Released online:

o1 Feb 2013

ISBN: 978-3-

89785-963-о

List price

Paperback

Publication date: o1 Feb 2013

ISBN: 978-389785-797-1

List price 
For more information see brill.com

Order information: Order online at brill.com +44330 333 0049 | customerservices@brill.com Submission information: brill.com/authors

Titles published by Brill | Fink, Brill | mentis or Brill | Schöningh: +49(o)715413279216| brill@brocom.de 